\title{
Paternal programming of breast cancer risk in daughters in a rat model: opposing effects of animal- and plant-based high-fat diets
}

Camile Castilho Fontelles ${ }^{1}$, Luiza Nicolosi Guido ${ }^{1}$, Mariana Papaléo Rosim¹ , Fábia de Oliveira Andrade ${ }^{1}$, Lu Jin², Jessica Inchauspe ${ }^{2}$, Vanessa Cardoso Pires ${ }^{1}$, Inar Alves de Castro ${ }^{1}$, Leena Hilakivi-Clarke², Sonia de Assis ${ }^{2}$ and Thomas Prates Ong ${ }^{1,3^{*}}$

\begin{abstract}
Background: Although males contribute half of the embryo's genome, only recently has interest begun to be directed toward the potential impact of paternal experiences on the health of offspring. While there is evidence that paternal malnutrition may increase offspring susceptibility to metabolic diseases, the influence of paternal factors on a daughter's breast cancer risk has been examined in few studies.

Methods: Male Sprague-Dawley rats were fed, before and during puberty, either a lard-based (high in saturated fats) or a corn oil-based (high in n-6 polyunsaturated fats) high-fat diet ( $60 \%$ of fat-derived energy). Control animals were fed an AIN-93G control diet (16\% of fat-derived energy). Their 50-day-old female offspring fed only a commercial diet were subjected to the classical model of mammary carcinogenesis based on 7,12-dimethylbenz[a]anthracene initiation, and mammary tumor development was evaluated. Sperm cells and mammary gland tissue were subjected to cellular and molecular analysis.

Results: Compared with female offspring of control diet-fed male rats, offspring of lard-fed male rats did not differ in tumor latency, growth, or multiplicity. However, female offspring of lard-fed male rats had increased elongation of the mammary epithelial tree, number of terminal end buds, and tumor incidence compared with both female offspring of control diet-fed and corn oil-fed male rats. Compared with female offspring of control diet-fed male rats, female offspring of corn oil-fed male rats showed decreased tumor growth but no difference regarding tumor incidence, latency, or multiplicity. Additionally, female offspring of corn oil-fed male rats had longer tumor latency as well as decreased tumor growth and multiplicity compared with female offspring of lard-fed male rats. Paternal consumption of animal- or plant-based high-fat diets elicited opposing effects, with lard rich in saturated fatty acids increasing breast cancer risk in offspring and corn oil rich in n-6 polyunsaturated fatty acids decreasing it. These effects could be linked to alterations in microRNA expression in fathers' sperm and their daughters' mammary glands, and to modifications in breast cancer-related protein expression in this tissue.
\end{abstract}

Conclusions: Our findings highlight the importance of paternal nutrition in affecting future generations' risk of developing breast cancer.

Keywords: Paternal diet, Breast cancer, High-fat diet, Female offspring

\footnotetext{
* Correspondence: tong@usp.br

${ }^{1}$ Department of Food and Experimental Nutrition, Faculty of Pharmaceutical

Sciences, University of São Paulo, Avenida Professor Lineu Prestes 580, Bloco

14, São Paulo, SP 05508-000, Brazil

${ }^{3}$ Food Research Center (FoRC), São Paulo 05508-000, Brazil

Full list of author information is available at the end of the article
} 


\section{Background}

Breast cancer is a global public health problem, with nearly 1.7 million new cases diagnosed in 2012, representing $25 \%$ of all cancers in women worldwide [1]. Its incidence is projected to rise significantly over the next 20 years despite current efforts to prevent the disease [2]. Although the precise reason for this growth is still not clear, it has been suggested that modern women's lifestyles, including postponing first pregnancy and having fewer children, can explain the increase [3].

Nutritional habits, such as adoption of Western dietary patterns, are also linked to increased breast cancer risk [4]. These patterns are characterized by low consumption of fruits and vegetables, increased energy intake, and decreased energy expenditure, leading to obesity, as well as increased intake of saturated fatty acids (SFA), n-6 polyunsaturated fatty acids (PUFA), and trans-fatty acids and decreased intake of n-3 polyunsaturated fats $[5,6]$. While the majority of epidemiological studies on nutrition and breast cancer risk have been focused on women's diet in adulthood, accumulating epidemiological and experimental evidence highlights early life experiences, including nutrition, as relevant factors for later breast cancer risk determination [7]. The developmental origins of this cancer have been considered predominantly from a maternal perspective, with emphasis placed on the impact of high fat or energy intake during gestation and lactation on female offspring mammary gland development and later breast cancer risk $[8,9]$.

Although males contribute half of the embryo's genome, only recently has interest begun to be directed toward the potential impact of paternal experiences on the health of offspring [10]. While experimental studies have shown that paternal malnutrition may increase the susceptibility of offspring to metabolic dysregulation, obesity, and cardiovascular diseases $[11,12]$, the influence of paternal factors on daughter's breast cancer risk has been examined in few studies. Among them, epidemiological studies show an association between higher paternal education level, older age, and smoking with increased rate of breast cancer in the daughters $[13,14]$.

Unlike the female production of germ cells that takes place predominantly in early life [15], male production of germ cells starts in utero, with mature sperm cells being produced throughout the entire reproductive life of the male [16]. Because spermatogenesis can be dramatically influenced by environmental factors, including malnutrition, obesity, and an exposure to toxic compounds, the father's health during preconception is now acknowledged as a critical factor in the context of the developmental origins of health and disease [17]. In addition to embryogenesis, gametogenesis comprises intense epigenetic (DNA methylation, histone modification, and microRNA [miRNA or miR] expression) remodeling [18, 19]. Thus, epigenetically inherited increased disease risk could be transmitted through the female as well as the male germline [20]. Specific windows within which male gametes would be especially prone to environmentally elicited epigenetic deregulation include prepuberty and the reproductive phase [21].

Given the marked increase in dietary fat intake over the past three decades [22], as well as the notion that different kinds of dietary fats can lead to different health outcomes [23], we designed this study to investigate whether, in rats, consumption of high levels of animalor vegetable-based fats by fathers would affect their daughters' risk of breast cancer. We also investigated the underlying cellular and molecular mechanisms. We fed male Sprague-Dawley rats, before and during puberty, either a lard-based (high in SFA) or a corn oil-based (high in n-6 PUFA) high-fat diet (60\% of fat-derived energy). Control animals were fed a control AIN-93G diet containing soybean oil as a fat source (16\% of fatderived energy). Male rats were mated with female rats that were consuming a commercial diet. We show that paternal consumption of these high-fat diets elicited opposing effects, with animal fat increasing and vegetable oil decreasing breast cancer risk in the offspring. These effects could be linked to alterations in miRNA expression in fathers' sperm and their daughters' mammary glands, as well as to modifications in breast cancerrelated protein expression in this tissue. These novel data show that paternal high-fat diets influence their female offspring's susceptibility to mammary cancer, with consumption of lard increasing and corn oil reducing daughters' mammary cancer risk. Thus, paternal diet before conception sets a stage for a daughter's risk of developing breast cancer.

\section{Methods \\ Experimental design}

This study was approved by the ethics committee on animal experiments of the Faculty of Pharmaceutical Sciences, University of São Paulo (protocol number CEUA/ FCF/381). Twenty-one-day-old male rats were divided into three groups ( $n=20$ rats per group): control rats (those fed the control AIN-93G diet, with $16 \%$ of total calories provided by lipids), lard-fed males (exposed to a high-SFA diet, with $60 \%$ of total calories provided mainly from lard), and corn oil-fed males (exposed to n-6 PUFA diet, with $60 \%$ of total calories provided mainly from corn oil). At 12 weeks of age, all male rats were switched to a chow diet and mated by housing one male with one female per cage. Pregnant female rats and their offspring consumed only commercial laboratory chow (Nuvital Nutrientes, Colombo, Brazil). Body weight and food intake were recorded two or three times per week. 


\section{Determination of the diets' lipid profiles}

The lipid profiles of the control, lard, and corn oil diets were determined according to the methods published by the Association of Official Analytical Chemists [24]. Fatty acids were esterified to fatty-acid methyl esters according to the method reported by Hartman and Lago [25], and their composition was analyzed with a gas chromatograph (GC 17A/Class GC 10; Shimadzu, Kyoto, Japan) equipped with a flame ionization detector and a SUPELCOWAX ${ }^{\circ}$ 10 fused silica capillary column $(30 \mathrm{~mm} \times 0.25 \mathrm{~mm}$ inner diameter; Sigma-Aldrich, St. Louis, MO, USA). The temperature was set at $170{ }^{\circ} \mathrm{C}$, raised to $225{ }^{\circ} \mathrm{C}$ at a rate of $1{ }^{\circ} \mathrm{C} /$ minute, and held for 25 minutes. The temperatures of the vaporizer and detector were $250{ }^{\circ} \mathrm{C}$ and $270{ }^{\circ} \mathrm{C}$, respectively. Helium was used as the carrier gas ( $1 \mathrm{ml} /$ minute). Identification of the fatty acids was performed by comparison of the retention times with the standard mixture of fatty-acid methyl esters. Each determination was performed in duplicate using two different samples for each diet.

\section{Insulin tolerance test}

The tests were performed at $0800 \mathrm{~h}$ after the rats were fasted for $12 \mathrm{~h}$, according to the method described by Takada et al. [26]. The insulin load $(75 \mathrm{mU} / 100$ g body weight) was injected as a bolus, and the blood glucose levels were determined at $0,3,6,9,12$, and 30 minutes after injection in male rats and their 50-day-old female offspring. The AUC was calculated according to the trapezoid rule [27].

\section{Mature spermatozoa collection and purification}

Control diet and lard- and corn oil-fed male rats were killed once females were pregnant, and the caudal epididymis was dissected for sperm collection. The cauda and vas deferens from male rats were collected, punctured, and transferred to tissue culture dishes containing M2 medium (M2 medium with HEPES, without penicillin and streptomycin, sterile-filtered, suitable for rat embryo; Sigma-Aldrich), where it was incubated for $1 \mathrm{~h}$ at $37^{\circ} \mathrm{C}$. Spermatozoa samples were washed with PBS and then incubated with somatic cell lysis buffer (SCLB; $0.1 \%$ SDS, $0.5 \%$ Triton X-100 in diethylpyrocarbonate water) for $1 \mathrm{~h}$, according to a protocol described by Goodrich et al. [28]. SCLB was rinsed off with two washes of PBS, and the purified spermatozoa sample (at least $95 \%$ purity as assessed by microscopy) was pelleted and used for miRNA extraction.

\section{Determination of daily sperm production}

The right testis was maintained at $-20{ }^{\circ} \mathrm{C}$ until processing to determine the daily sperm production. The technique proposed by Robb et al. [29] is based on the resistance of elongated spermatids present in phases
17-19 of spermatogenesis to intense mechanical stress due to the high compaction of chromatin.

\section{Sperm morphological analyses}

According to the method of Seed et al. [30], the epididymis was previously frozen at $-20{ }^{\circ} \mathrm{C}$, underwent incision, and was subsequently immersed in PBS to promote the dissemination of gametes to the aqueous medium. Then the obtained solution was placed on slides for examination by light microscopy. Two hundred sperm per animal were analyzed microscopically at $\times 400$ magnification.

\section{Mammary gland harvesting}

Abdominal mammary glands of female offspring of control diet- and lard- and corn oil-fed male rats $(n=6$ per group) were collected on postnatal day 50 and used for preparing mammary whole mounts and miRNA and protein extraction.

Analysis of mammary gland morphology and development Whole-mount preparations of the fourth abdominal mammary gland from 50-day-old female offspring $(n=5 /$ group) were obtained, and the epithelial elongation and number of terminal end buds (TEBs) were determined as described by de Assis et al. [31].

\section{Mammary tumor induction}

Mammary tumors were induced in 50-day-old female rat offspring ( $n=24$ rats/group) by administration of 7,12-dimethylbenz[a]anthracene (DMBA, $50 \mathrm{mg} / \mathrm{kg}$ body weight; Sigma-Aldrich). The carcinogen was dissolved in corn oil and administered by oral gavage. Animals were examined for mammary tumors by palpation twice per week. Latency of tumor appearance, the number of animals with tumors, and the number of tumors per animal (multiplicity) were evaluated. The tumor volume was calculated with tumor measures of length $(a)$, height $(b)$, and width $(c)$ taken with a caliper rule once per week since tumor appearance and throughout the experiment. The formula $(1 / 6 \times 3.14) \times(a \times b \times c)$ was used to calculate the tumor volume, as described by Spang-Thomsen et al. [32]. The tumor growth rate was calculated using the measured volumes of each tumor at a given week $(d)$ and the subsequent week $(e)$ of appearance using the formula $[(e-d) / d] \times 100$. Those animals in which tumor burden approximated $10 \%$ of total body weight were killed. All others animals were killed 19 weeks after carcinogen administration.

\section{Analysis of mammary gland and tumor cell proliferation and apoptosis in female offspring}

Cell proliferation was evaluated in mammary glands (ducts and lobules) and tumors from 50-day-old female offspring ( $n=4 /$ group) by Ki-67 immunohistochemistry. 
After being harvested, mammary tissue was directly fixed in $10 \%$ buffered formalin, embedded in paraffin, and sectioned. Sections were then deparaffinized in xylene and hydrated through graded ethanol. Antigen retrieval was performed with $10 \mathrm{mM}$ citrate buffer, $\mathrm{pH} 6$, for 20 minutes in a pressure cooker. Peroxidase blocking was performed with $10 \% \mathrm{H}_{2} \mathrm{O}_{2}$ for 10 minutes, and nonspecific binding was blocked for $1 \mathrm{~h}$ with $1 \%$ skimmed milk in PBS. Sections were incubated overnight with anti-rat Ki-67 primary antibody (Abcam, Cambridge, UK) at a 1:50 dilution. After washes, sections were incubated with the LSAB 2 System-HRP kit (Dako, Carpinteria, CA, USA) according to the manufacturer's instructions, stained with 3,3'-diaminobenzidine in chromogenic solution (Dako) for 10 minutes, washed, and counterstained for 1.5 minutes with hematoxylin. Cell proliferation was quantified by assessing the number of Ki-67-positive cells among 1000 cells. The slides were evaluated using ImageJ software (National Institutes of Health, Bethesda, MD, USA). Apoptosis analysis was conducted in mammary glands (ducts and lobules) and tumors from 50-day-old female offspring ( $n=4 /$ group), according to the method described by Elmore et al. [33], using ImageJ software. Results are presented as mean number of apoptotic cells per 1000 cells.

\section{microRNA expression profile analysis}

Total RNA from paternal sperm and their female offspring's total mammary gland was extracted using the miRNeasy Mini Kit (QIAGEN, Valencia, CA, USA) according to the manufacturer's instructions. RNA samples were quantified and stored at $-80{ }^{\circ} \mathrm{C}$ until use. miRNA arrays were performed at the Genomics and Epigenomics Shared Resources at Georgetown University using Applied Biosystems TaqMan Array Rodent MicroRNA arrays (Life Technologies, Carlsbad, CA, USA) to generate the miRNA expression profiles for each experimental group. The TaqMan ${ }^{\circ}$ Array Rodent MicroRNA A + B Cards Set v3.0 is a two-card set containing a total of 384 TaqMan $^{\circ}$ MicroRNA assays per card (Life Technologies). The set enables accurate quantitation of 641 and 373 unique miRNAs for rat. There are three TaqMan ${ }^{\bullet}$ MicroRNA Assay endogenous controls for each species on each array to aid in data normalization [34]. The geNorm algorithm was applied to those endogenous controls to determine the optimal number of stable controls. The geometric mean of these selected controls was used for array normalization. To conduct further statistical analysis, the normalized value was $\log$-transformed to meet the $t$ test requirement. Statistical analysis was conducted using the limma package in $\mathrm{R}$ [35]. miRNAs that had a false discovery rate $<0.1$ were considered as significantly altered and selected for further analysis. Target prediction for miRNAs of interest was conducted using TargetScan (release 6.2). The predicted targeted messenger RNA (mRNA) list was then uploaded to Ingenuity Pathway Analysis (IPA; QIAGEN Silicon Valley, Redwood City, CA, USA) for gene set enrichment analysis. We selected the top canonical pathways for further analysis.

\section{Analysis of protein levels in mammary glands of female offspring}

Protein levels of $50 \mathrm{ng} / \mu \mathrm{l}$ were assessed by Western blot analysis in total mammary glands obtained from 50-dayold female rats ( $n=5$ per group). Total protein was extracted from mammary tissues using radioimmunoprecipitation assay buffer with protease inhibitor (Roche, Basel, Switzerland), glycerophosphate $(10 \mathrm{mM})$, sodium orthovanadate $(1 \mathrm{mM})$, pyrophosphate $(5 \mathrm{mM})$, and phenylmethylsulfonyl fluoride $(1 \mathrm{mM})$. The samples were mixed with the buffer for 5 minutes, then incubated on ice for 30 minutes and centrifuged for 10 minutes at high speed. Protein in the supernatant was quantified using Pierce bicinchoninic acid protein assay reagent (Thermo Scientific, Rockford, IL, USA). Protein extracts were resolved on a 4-12\% gradient denaturing polyacrylamide gel (SDS-PAGE). Proteins were transferred using the Invitrogen iBlot ${ }^{\circ}$ 7-Minute Dry Blotting System (Life Technologies) and blocked with $5 \%$ nonfat dry milk for $1 \mathrm{~h}$ at room temperature. Membranes were incubated with the specific primary antibodies at $4{ }^{\circ} \mathrm{C}$ overnight. After several washes, the membranes were incubated with HRP-conjugated secondary antibody (1:5000; Santa Cruz Biotechnology, Dallas, TX, USA) at room temperature for $1 \mathrm{~h}$. Membranes were developed using HyGLO chemiluminescent HRP antibody detection reagent (Denville Scientific Inc., Metuchen, NJ, USA), and exposed to Kodak autoradiography films (Carestream Health, Rochester, NY, USA). The optical density of the bands was quantified using Quantity One software (BioRad Laboratories, Hercules, CA, USA). To control for equal protein loading, expression of the proteins of interest was normalized to the $\beta$-actin signal.

\section{Statistical analysis}

Results are expressed as the mean \pm SEM, and all analyses were conducted with the limma package in $\mathrm{R}$. Multiple-group comparisons were performed using oneway analysis of variance (ANOVA) followed by a least significant difference (LSD) test, and two-group comparisons were performed using Student's $t$ test. Repeatedmeasures ANOVA was applied for caloric intake data evaluation, and Kaplan-Meier curves and log-rank tests were applied for determining differences in tumor incidence. For all data analyses, $p \leq 0.05$ was applied as the threshold for statistical significance. 


\section{Results}

\section{Paternal dietary and health parameters}

Compared with control diet-fed male rats, the ones that were on the lard- or corn oil-based high-fat diets consumed more $(p \leq 0.05)$ SFA (predominantly palmitic [C16:0] and stearic [C18:0] acids), monounsaturated fatty acids (MUFA) (predominantly oleic acid [C18:1n9c]) and PUFA (predominantly linoleic acid [C18:2n6c]) (Fig. 1a). Corn oil-fed male rats consumed less $(p \leq 0.05)$ SFA (predominantly palmitic [C16:0] and stearic [C18:0] acids) and MUFA (predominantly oleic acid [C18:1n9c]) and more $(p \leq 0.05)$ PUFA (predominantly linoleic acid [C18:2n6c]) than the lard-fed male rats (Fig. 1a). Daily caloric intake was approximately $7 \%$ higher $(p \leq 0.05)$ in both lard- and corn oil-fed male rats than in control diet-fed male rats (data not shown). Although lard- and corn oil-fed male rats consumed nearly the same amount of calories per day, lard-fed male rats gained more $(p \leq 0.05)$ weight than control diet- and corn oil-fed male rats $(p \leq 0.05)$ (Table 1$)$. There was no difference $(p>0.05)$ between control dietand corn oil-fed male rats regarding weight gain. Both lard- and corn oil-fed male rats had greater $(p \leq 0.05)$ abdominal, retroperitoneal, and epididymal fat pad weights than control diet-fed male rats (Table 1). Compared with lard-fed male rats, corn oil-fed male rats had lesser $(p \leq$ $0.05)$ epididymal fat pad weights, but there was no difference $(p>0.05)$ in abdominal or retroperitoneal fat pad weights (Table 1). Further, lard-fed male rats had lesser testicle $(p \leq 0.05)$, epididymis $(p \leq 0.05)$, and seminal vesicle $(p \leq 0.08)$ weights than the control diet- and corn oil-fed male rats (Table 1$)$. There was no difference $(p>$ 0.05 ) between control diet- and corn oil-fed male rats regarding these parameters (Table 1). Lard-fed male rats also had fewer $(p \leq 0.05)$ normal sperm cells and lower $(p \leq 0.05)$ daily sperm production than control diet- and corn oil-fed male rats (Table 1 ). There was no difference $(p>0.05)$ between control diet- and corn oil-fed male rats regarding these parameters (Table 1 ). Both lard- and corn oil-fed male rats had higher $(p \leq 0.05)$ fasting glucose levels than control diet-fed male rats (Table 1$)$. There was no difference $(p>0.05)$ between lard- and corn oil-fed male rats regarding this parameter (Table 1). Further, in the insulin tolerance test, lard- and corn oil-fed male rats had higher $(p \leq 0.05)$ AUCs than control diet-fed male rats (Fig. 1b), indicating that they were insulin-intolerant. There was no difference $(p>0.05)$ between lard- and corn oil-fed male rats regarding this parameter (Fig. 1b).

\section{Female offspring health parameters}

Female offspring of both lard- and corn oil-fed male rats had greater birth weight $(p \leq 0.05)$ and greater weight gain ( $p \leq 0.05 ; p \leq 0.08$ for offspring of corn oil-fed male rats) than offspring of control diet-fed male rats (Table 1 ). There was no difference $(p>0.05)$ between female offspring of lard- and corn oil-fed male rats regarding birth weight (Table 1). Female offspring of corn oil-fed male rats had less $(p \leq 0.05)$ weight gain than offspring of lard-fed male rats (Table 1). Similarly to the male rats, female offspring of both the lard-fed and the corn oil-fed male rats had greater $(p \leq 0.05)$ retroperitoneal fat weights than offspring of control diet-fed male rats (Table 1). There was no difference $(p>0.05)$ between female offspring of lardor corn oil-fed male rats regarding this parameter (Fig. 1c). Female offspring of lard-fed male rats had higher ( $p \leq$ $0.05)$ fasting glucose levels (Table 1$)$ and higher $(p \leq 0.05)$ AUCs than female offspring of control diet- or corn oil-fed
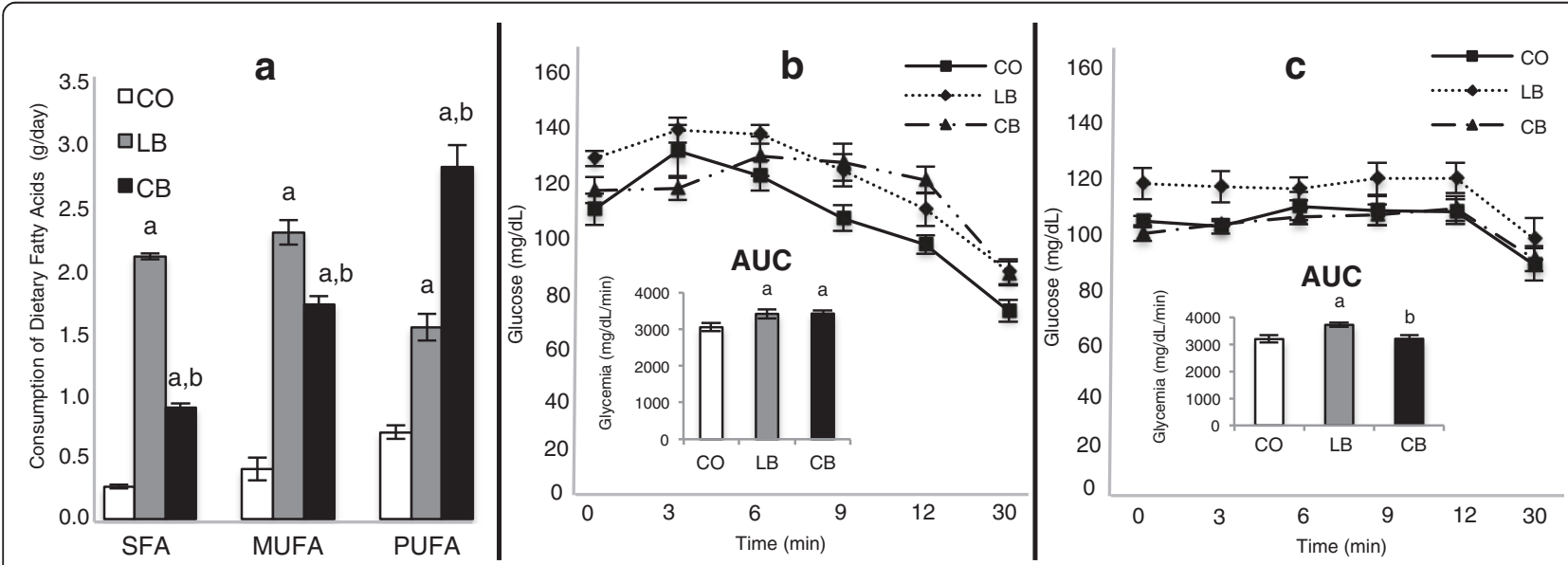

Fig. 1 Paternal fatty-acid consumption and insulin tolerance test. a Male rats fed a control diet (CO) or a lard-based (LB) or corn oil-based (CB) high-fat diet consumption of dietary fats (saturated fatty acids [SFA], monounsaturated fatty acids [MUFA], and polyunsaturated fatty acids [PUFA]) ( $n=20$ per group). $\mathbf{b}$ Insulin tolerance test (ITT) of the CO-, LB-, and CB-fed male rats ( $n=6$ per group). Inset: ITT is shown as the AUC. c Fifty-day-old female offspring ( $n=6$ per group). Inset: ITT is shown as the AUC. Statistically significant difference $(p \leq 0.05)$ compared with ${ }^{a} C O$ and ${ }^{b} \mathrm{LB}$, according to analysis of variance followed by a least significant difference test. The data are expressed as mean \pm SEM 
Table 1 Health parameters of male rats and their 50-day-old female offspring in control diet, lard-based diet, and corn oil-based diet groups

\begin{tabular}{|c|c|c|c|}
\hline & $\mathrm{CO}$ & LB & $C B$ \\
\hline \multicolumn{4}{|l|}{ Male rats } \\
\hline Weight gain & $363.1 \pm 6.4 \mathrm{~g}$ & $398.2 \pm 12.0 \mathrm{~g}^{\mathrm{a}}$ & $369.4 \pm 7.8 \mathrm{~g}^{\mathrm{b}}$ \\
\hline \multicolumn{4}{|l|}{ Fat weight } \\
\hline Abdominal fat & $1.4 \pm 0.1 \mathrm{~g} / 100 \mathrm{~g}$ body weight & $2.7 \pm 0.2 \mathrm{~g} / 100 \mathrm{~g}$ body weight ${ }^{\mathrm{a}}$ & $2.6 \pm 0.2 \mathrm{~g} / 100 \mathrm{~g}$ body weight ${ }^{\mathrm{a}}$ \\
\hline Retroperitoneal fat & $0.8 \pm 0.1 \mathrm{~g} / 100 \mathrm{~g}$ body weight & $1.9 \pm 0.1 \mathrm{~g} / 100 \mathrm{~g}$ body weight ${ }^{\mathrm{a}}$ & $1.7 \pm 0.2 \mathrm{~g} / 100 \mathrm{~g}$ body weight ${ }^{\mathrm{a}}$ \\
\hline Epididymal fat & $1.2 \pm 0.1 \mathrm{~g} / 100 \mathrm{~g}$ body weight & $2.7 \pm 0.1 \mathrm{~g} / 100 \mathrm{~g}$ body weight ${ }^{\mathrm{a}}$ & $2.0 \pm 0.2 \mathrm{~g} / 100 \mathrm{~g}$ body weight ${ }^{\mathrm{a}, \mathrm{b}}$ \\
\hline \multicolumn{4}{|l|}{ Reproductive organs } \\
\hline Testicle & $0.45 \pm 0.01 \mathrm{~g} / 100 \mathrm{~g}$ body weight & $0.40 \pm 0.01 \mathrm{~g} / 100 \mathrm{~g}$ body weight ${ }^{\mathrm{a}}$ & $0.45 \pm 0.01 \mathrm{~g} / 100 \mathrm{~g}$ body weight ${ }^{\mathrm{b}}$ \\
\hline Epididymis & $0.14 \pm 0.00 \mathrm{~g} / 100 \mathrm{~g}$ body weight & $0.13 \pm 0.00 \mathrm{~g} / 100 \mathrm{~g}$ body weight ${ }^{\mathrm{a}}$ & $0.14 \pm 0.00 \mathrm{~g} / 100 \mathrm{~g}$ body weight ${ }^{\mathrm{b}}$ \\
\hline Seminal vesicle & $0.33 \pm 0.01 \mathrm{~g} / 100 \mathrm{~g}$ body weight & $0.29 \pm 0.02 \mathrm{~g} / 100 \mathrm{~g}$ body weight ${ }^{c}$ & $0.33 \pm 0.02 \mathrm{~g} / 100 \mathrm{~g}$ body weight ${ }^{\mathrm{d}}$ \\
\hline Sperm morphology (\% normal) & $66.4 \pm 2.8 \%$ & $50.1 \pm 3.0 \%{ }^{\mathrm{a}}$ & $70.9 \pm 2.9 \%^{\mathrm{b}}$ \\
\hline Daily sperm production, $n /$ testicle/day & $31 \pm 1.9 \times 10^{6}$ & $23 \pm 0.9^{\mathrm{a}} \times 10^{6}$ & $29 \pm 0.8^{\mathrm{b}} \times 10^{6}$ \\
\hline Fasting glycemia & $100.8 \pm 3 \mathrm{mg} / \mathrm{dl}$ & $124.6 \pm 4 \mathrm{mg} / \mathrm{dl}^{\mathrm{a}}$ & $116.1 \pm 3 \mathrm{mg} / \mathrm{dl}^{\mathrm{a}}$ \\
\hline \multicolumn{4}{|l|}{ 50-day-old female offspring } \\
\hline Birth weight & $8.0 \pm 1.5 \mathrm{~g}$ & $8.8 \pm 1.0 \mathrm{~g}^{\mathrm{a}}$ & $9.1 \pm 1.5 \mathrm{~g}^{\mathrm{a}}$ \\
\hline Weight gain & $138.9 \pm 1.5 \mathrm{~g}$ & $147.0 \pm 1.2 \mathrm{~g}^{\mathrm{a}}$ & $142.1 \pm 1.1 \mathrm{~g}^{\mathrm{b}, \mathrm{c}}$ \\
\hline Retroperitoneal fat & $0.9 \pm 0.1 \mathrm{~g} / 100 \mathrm{~g}$ body weight & $1.1 \pm 0.0 \mathrm{~g} / 100 \mathrm{~g}$ body weight ${ }^{\mathrm{a}}$ & $1.2 \pm 0.1 \mathrm{~g} / 100 \mathrm{~g}$ body weight ${ }^{\mathrm{a}}$ \\
\hline Fasting glycemia & $106.4 \pm 2.0 \mathrm{mg} / \mathrm{dl}$ & $112.5 \pm 1.9 \mathrm{mg} / \mathrm{dl}^{\mathrm{a}}$ & $106.3 \pm 1.2 \mathrm{mg} / \mathrm{dl}^{\mathrm{b}}$ \\
\hline
\end{tabular}

Abbreviations: $C B$ rats fed a corn oil-based high-fat diet and their offspring, $C O$ rats fed a control diet and their offspring, $L B$ rats fed a lard-based high-fat diet and their offspring

Statistically significant difference $(p \leq 0.05)$ compared with ${ }^{\mathrm{a}} \mathrm{CO}$ and ${ }^{\mathrm{b}} \mathrm{LB}$, according to analysis of variance followed by least significant difference test. Marginal difference $(p \leq 0.08)$ compared with ${ }^{c} \mathrm{CO}$ and ${ }^{\mathrm{d}} \mathrm{LB}$, according to $t$ test. The data are expressed as mean \pm SEM ( $n=20$ per group)

male rats (Fig. 1c). There was no difference $(p>0.05)$ between female offspring of control diet- and corn oil-fed male rats regarding these parameters (Table 1 and Fig. 1c).

\section{Female offspring mammary gland morphology}

Mammary gland morphology was assessed on the basis of mammary whole mounts obtained from 50-day-old female offspring. Both elongation of the mammary epithelial tree (Fig. 2c) and the number of TEBs (Fig. 2d) were higher $(p \leq 0.05)$ in female offspring of lard-fed male rats than in female offspring of control diet- and corn oil-fed male rats. There was no difference $(p>0.05)$ between female offspring of control diet- and corn oilfed male rats regarding these parameters (Fig. $2 \mathrm{c}$ and d).

\section{Female offspring mammary gland tumors data}

Mammary tumors in the female offspring were induced by administering the carcinogen DMBA. Female offspring of lard-fed male rats had increased mammary tumor incidence $(p \leq 0.05)$ compared with offspring of both control diet- and corn oil-fed male rats (Fig. 3a). There was no statistical difference $(p>0.05)$ between female offspring of control diet- and corn oil-fed male rats regarding tumor incidence. Female offspring of corn oil-fed male rats exhibited longer $(p \leq 0.05)$ tumor latency and lower tumor multiplicity $(p \leq 0.05)$ than female offspring of lard-fed male rats (Fig. 3b and d). Compared with female offspring of control diet-fed male rats, female offspring of lard- and corn oil-fed male rats did not show differences $(p>0.05)$ regarding tumor latency and multiplicity. Further, female offspring of corn oil-fed male rats showed less $(p \leq 0.05)$ tumor growth in the first week of tumor appearance than offspring of both control diet- and lard-fed male rats (Fig. 3c). There was no statistical difference $(p>0.05)$ between offspring of control diet- and lard-fed male rats regarding tumor growth. Additionally, there was no statistical difference among groups in the tumor growth rate for the remaining experimental weeks.

\section{Female offspring mammary gland and tumor cell proliferation and apoptosis}

Female offspring of lard-fed male rats exhibited an increased $(p \leq 0.06)$ number of proliferative cells (Fig. $4 \mathrm{~b}$ ) and a decreased $(p \leq 0.05)$ number of apoptotic cells (Fig. 4e) in mammary gland lobules compared with female offspring of control diet- and corn oil-fed male rats. There was no difference $(p>0.05)$ between female offspring of control diet- and corn oil-fed male rats regarding these parameters (Fig. $4 \mathrm{~b}$ and e). Further, there was no difference $(p>0.05)$ in cell proliferation and apoptosis in mammary gland ducts among female offspring of all groups. Female offspring of both lard- and 


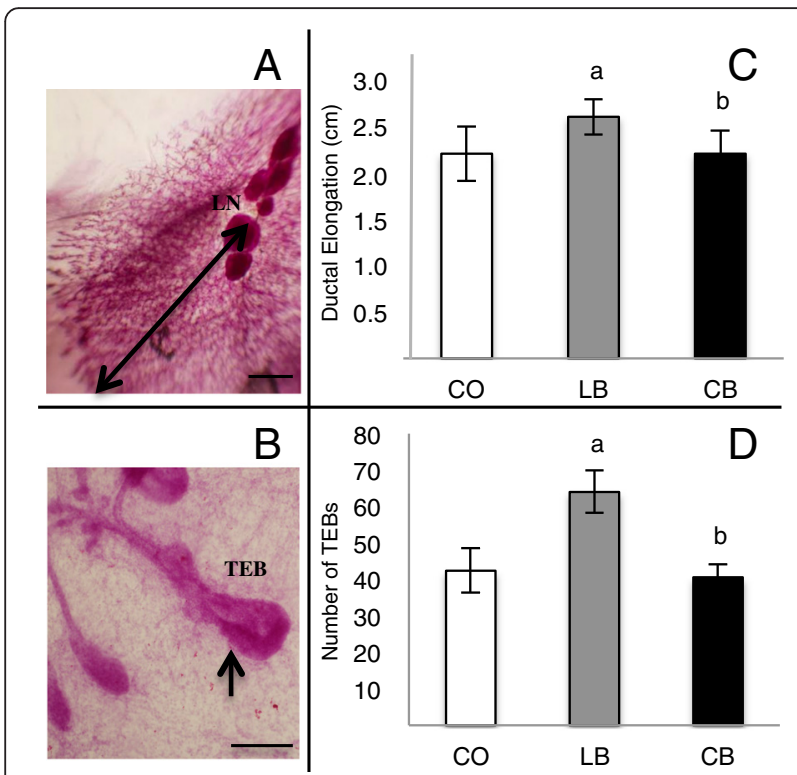

Fig. 2 Mammary gland development of 50-day-old female offspring of control diet (CO)-, lard (LB)-, and corn oil (CB)-fed male rats. a Histological depiction of the fourth abdominal mammary gland showing ductal elongation, indicated by arrow. $\mathbf{b}$ Terminal end buds (TEBs), indicated by arrows. $\mathbf{c}$ Ductal elongation. $\mathbf{d}$ Number of TEBs. All values are expressed as the mean \pm SEM. Statistically significant difference $(p \leq 0.05)$ compared with ${ }^{\mathrm{a}} \mathrm{CO}$ and ${ }^{\mathrm{b}} \mathrm{LB}$, according to analysis of variance followed by a least significant difference test. The data are expressed as mean \pm SEM ( $n=5$ per group)

corn oil-fed male rats exhibited a decreased $(p \leq 0.05)$ number of apoptotic cells (Fig. 4f) in mammary tumors compared with female offspring of control diet-fed male rats. There was no difference $(p>0.05)$ between female offspring of lard- and corn oil-fed male rats regarding this parameter (Fig. 4f). In addition, there was no difference $(p>0.05)$ among groups regarding cell proliferation in the mammary tumors (Fig. 4c).

\section{miRNA expression profile in fathers' sperm cells and in their daughters' mammary glands}

To compare the outcomes of the distinct paternal highfat diets on the basis of miRNA expression, Applied Biosystems TaqMan Rodent MicroRNA arrays were used to generate the miRNA profile for lard- and corn oil-fed fathers' sperm cells, as well as for their respective daughters' mammary glands. The microarray data are deposited in the Gene Expression Omnibus (GEO) public repository under accession number [GEO:GSE77012]. Corn oil-fed male rats had 89 downregulated $(p \leq 0.05)$ miRNAs in the sperm compared with lard-fed male rats (Fig. 5a). Furthermore, female offspring of corn oil-fed male rats had 21 downregulated $(p \leq 0.05)$ and 2 upregulated $(p \leq 0.05)$ miRNAs in their mammary glands compared with female offspring of lard-fed male rats (Fig. 5b). There were three miRNAs that were downregulated in both the sperm and

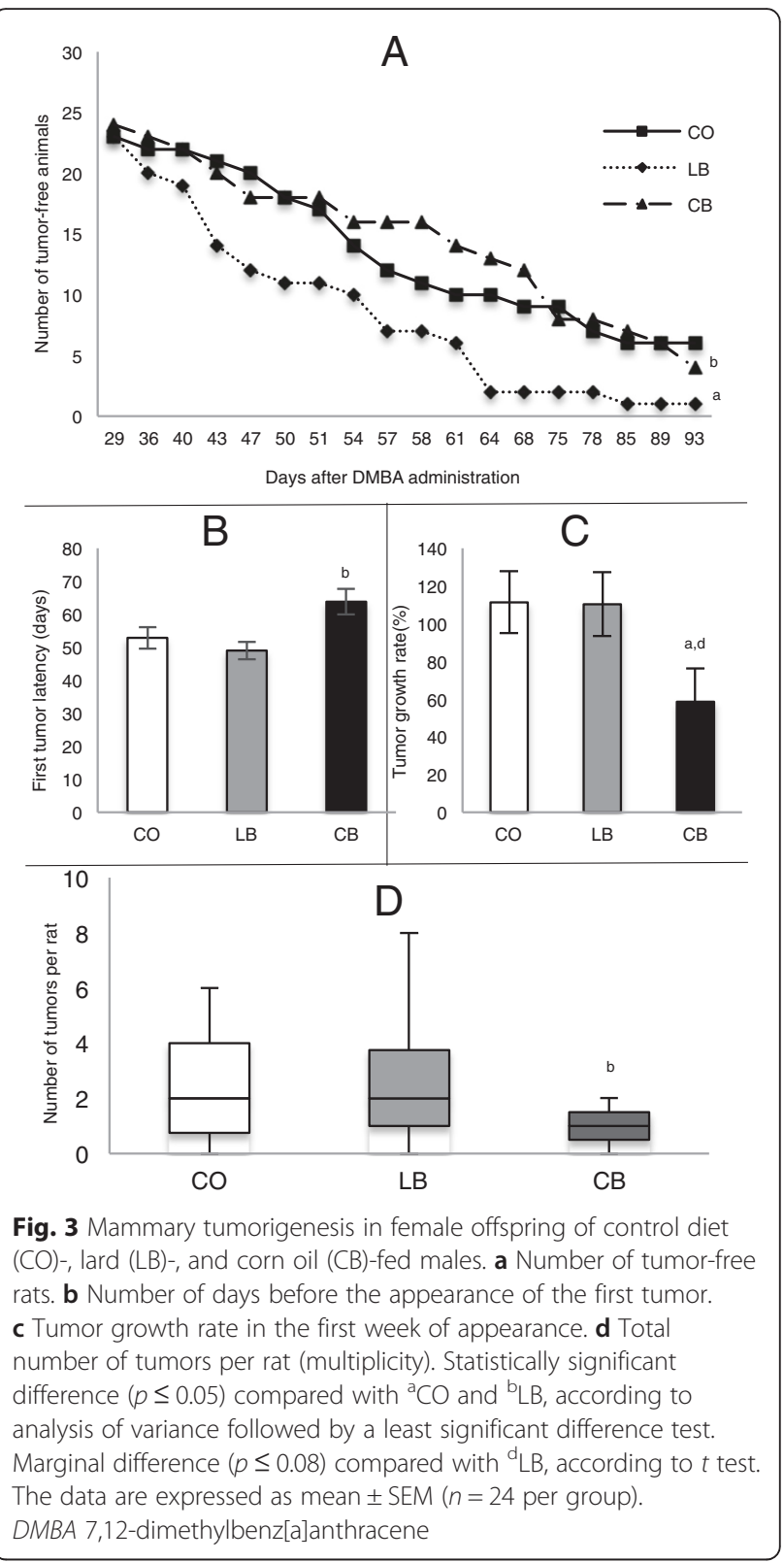

the mammary glands of the corn oil-fed fathers and their daughters, respectively: miR-1897-5p, miR-219-1-3p, and miR-376a\#. IPA (Additional file 1: Table S1) indicated that these miRNAs could regulate signaling pathways associated with key physiological processes such as growth hormone, phosphatase and tensin homolog (PTEN), and prolactin signaling, as well as disease processes such as Huntington's disease, cardiac hypertrophy, type 2 diabetes mellitus, and breast cancer.

Protein expression in female offspring mammary gland Since miR-1897-5p, miR-219-1-3p, and miR-376a\# can directly or indirectly modulate several targets (shown in Additional file 1: Table S1), we decided to perform 


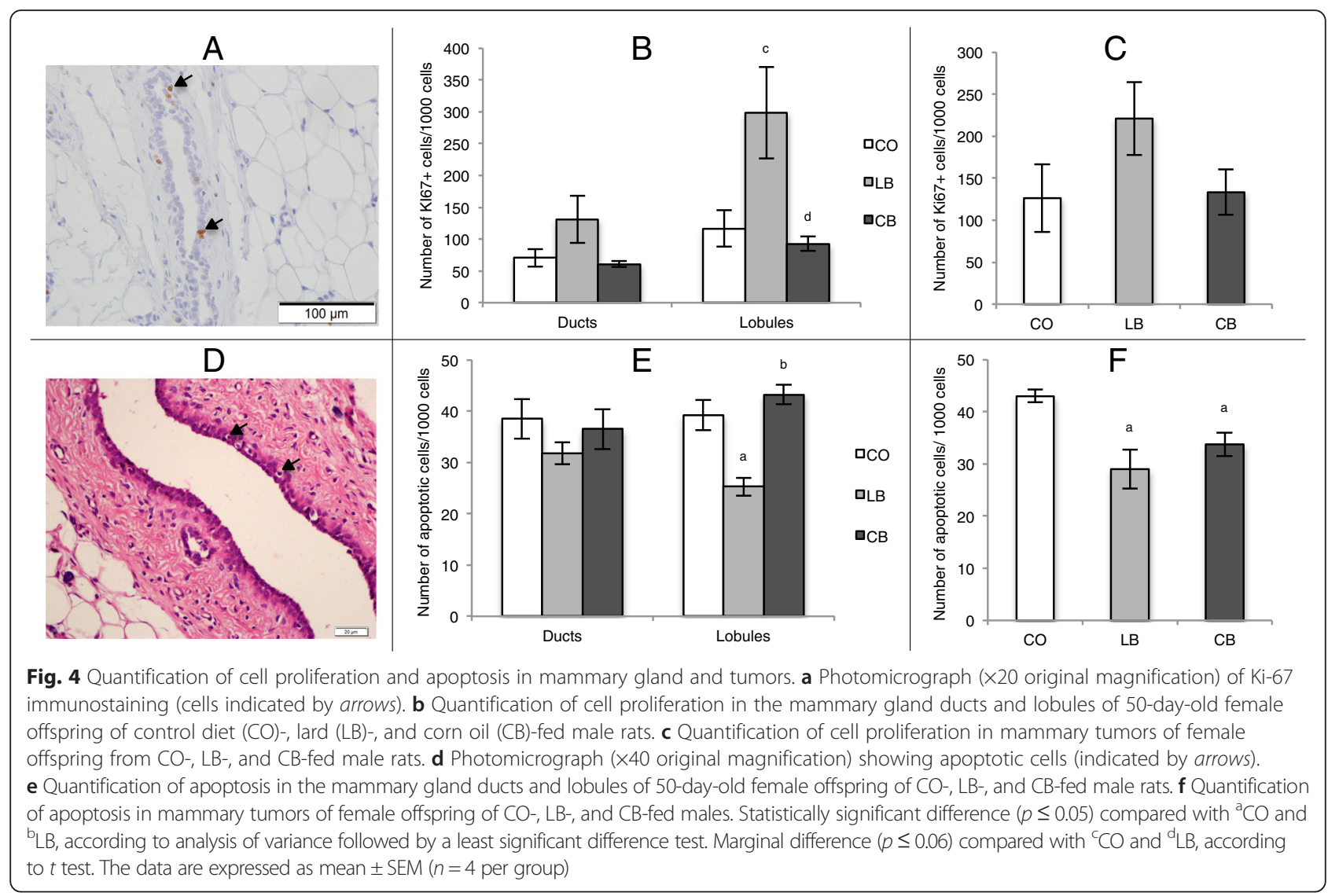

Western blot analysis of the following proteins linked to breast cancer: CCAAT/enhancer-binding protein beta $(\mathrm{Cebp} \beta)$, caspase 3 (Casp3), insulin-like growth factor 1 receptor (Igf1r), protein kinase D1 (Pkd1), and transforming growth factor, beta receptor I (Tgf $\beta r 1)$. On the one hand, there was no difference $(p>0.05)$ among female offspring of the control diet-, lard-, and corn oilfed male rats regarding $\operatorname{Cebp} \beta$, Casp3, and Igf1r levels (data not shown). On the other hand, female offspring of the corn oil-fed male rats had higher $(p \leq 0.05)$ Pkd1 levels in the mammary glands than female offspring of lard-fed, but not control diet-fed, male rats (Fig. 6). There was no difference $(p>0.05)$ between female offspring of control diet- and lard-fed male rats regarding this protein (Fig. 6). In addition, Tgf $\beta r 1$ levels were significantly increased in the offspring of lard-fed male rats (Fig. 6) compared with offspring of both control diet-fed $(p \leq 0.05)$ and corn oil-fed $(p \leq 0.06)$ male rats. There was no difference $(p>0.05)$ between female offspring of corn oil-fed and control diet-fed male rats regarding this protein (Fig. 6). Interestingly, both proteins are involved in regulating epithelial-to-mesenchymal transition (EMT): Pkd1 inhibits this process [36], and Tgfßr1 promotes it [37].

We further explored if Tgf $\beta$ and key regulators of its activity were altered by measuring protein levels of $\mathrm{v}$-akt murine thymoma viral oncogene (Akt), cofilin (Cfl), v-raf leukemia viral oncogene (c-Raf), extracellular signalregulated kinase 1/2 (Erk1/2), phosphorylated mitogenactivated protein kinase 8 (p-Jnk), mitogen-activated protein kinase $4(\mathrm{Mkk} 4)$, mechanistic target of rapamycin (Mtor), mitogen-activated protein kinase 14 (p38), phosphorylated Smad family member 3/Smad family member 3 (p-Smad3/Smad3) ratio, and Harvey rat sarcoma virus oncogene (Ras). Tgf $\beta$ protein expression was higher $(p \leq$ $0.05)$ in the mammary glands of the female offspring of lard-fed male rats than in the offspring of control dietand corn oil-fed male rats. There was no difference $(p>$ $0.05)$ between female offspring of corn oil- and control diet-fed male rats regarding this protein (Fig. 6). Further, the levels of Akt and p-Jnk were higher $(p \leq 0.05)$ in the female offspring of lard-fed male rats than in female offspring of control diet-fed male rats (Fig. 6). There was no difference $(p>0.05)$ in female offspring of corn oil-fed male rats and the offspring of control diet- and lard-fed male rats regarding these proteins (Fig. 6). Female offspring of corn oil-fed male rats had lower levels of Mtor, Mkk4 $(p \leq 0.06)$, and $\mathrm{p}-\mathrm{Smad} 3 / \mathrm{Smad} 3(p \leq 0.05)$ than female offspring of lard-fed, but not control diet-fed, male rats (Fig. 6). There was no difference $(p>0.05)$ between female offspring of control diet- and lard-fed male rats 


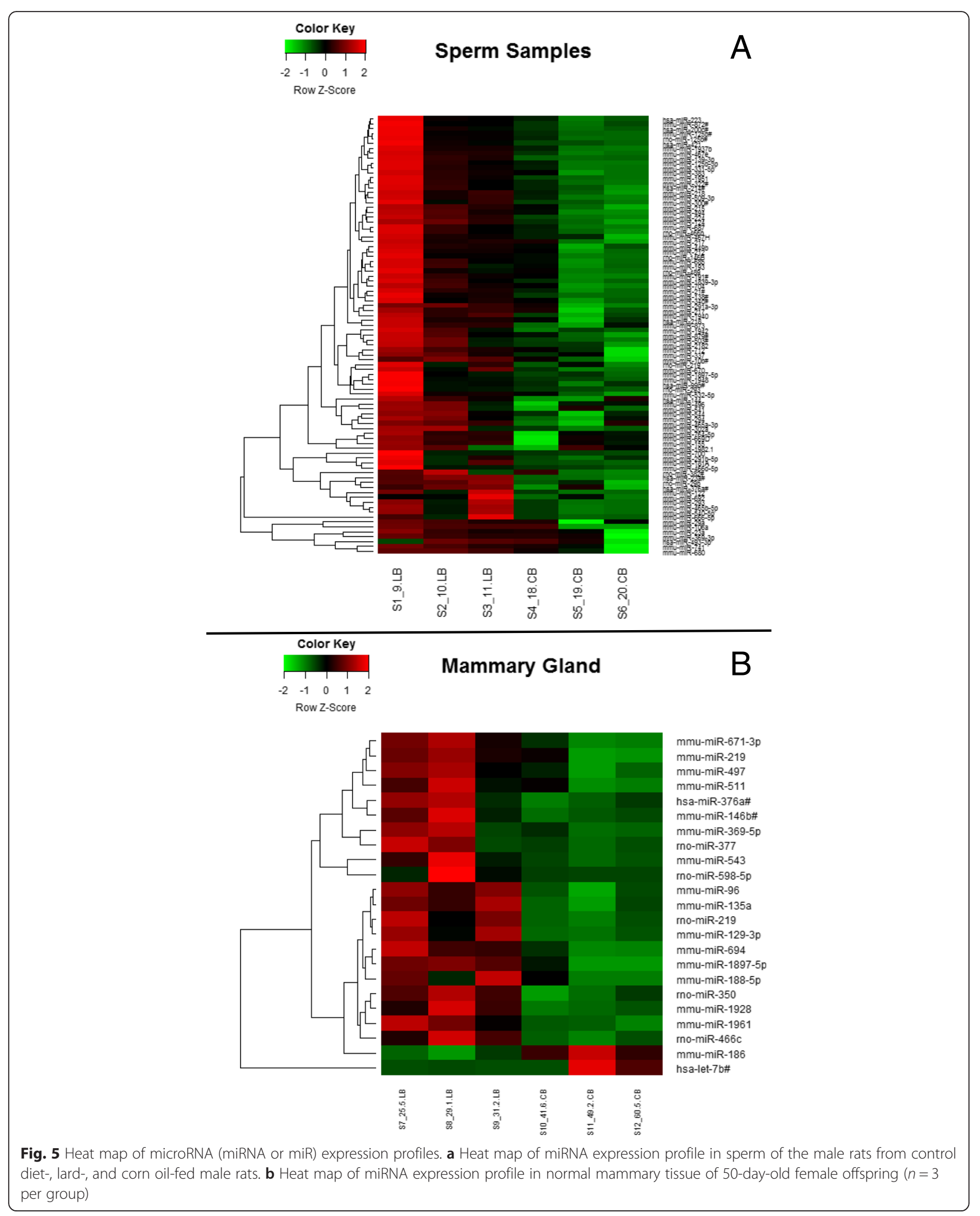




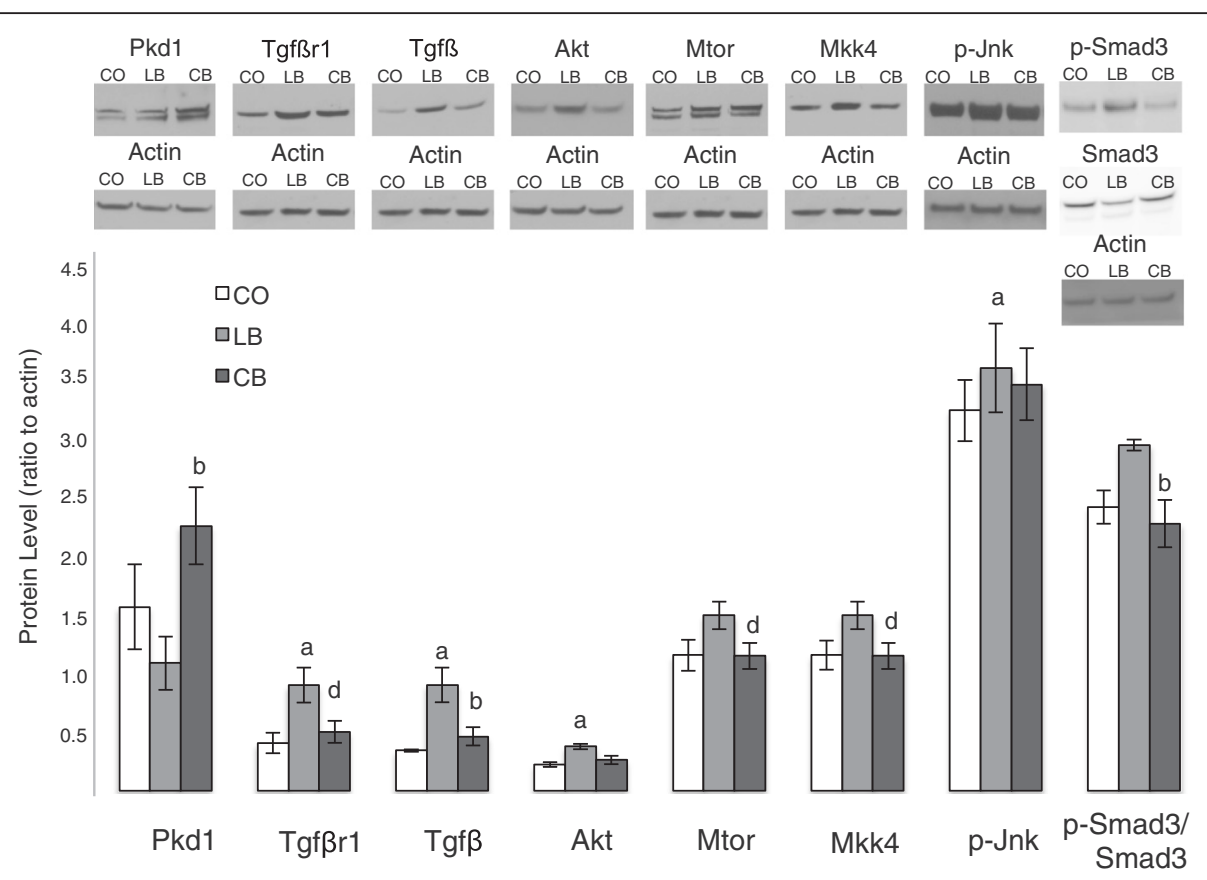

Fig. 6 Protein alterations associated with microRNA (miRNA) expression. Western blot analysis of protein kinase D1 (Pkd1), transforming growth factor, beta receptor I (Tgf $\beta r 1)$, transforming growth factor beta (Tgf $\beta$ ), v-akt murine thymoma viral oncogene (Akt), mechanistic target of rapamycin (Mtor), mitogen-activated protein kinase kinase 4 (Mkk4), phosphorylated mitogen-activated protein kinase 8 (p-Jnk), and phosphorylated Smad family member 3/Smad family member 3 ( $\mathrm{p}$-Smad3/Smad3) ratio protein expression in mammary glands of 50-day-old female offspring of control diet (CO)-, lard (LB)-, and corn oil (CB)-fed male rats. Statistically significant difference $(p \leq 0.05)$ compared with ${ }^{\mathrm{a}} \mathrm{CO}$ and ${ }^{\mathrm{b}} \mathrm{LB}$, according to analysis of variance followed by a least significant difference test. Marginal difference $(p \leq 0.06)$ compared with ${ }^{\mathrm{L}} \mathrm{LB}$, according to $t$ test. The data are expressed as mean \pm $\operatorname{SEM}(n=5$ per group)

regarding these proteins (Fig. 6). In addition to promoting EMT, all these altered proteins are involved in increasing cell survival, growth, migration, and invasion.

\section{Discussion}

Breast cancer is a complex disease with a multifactorial etiology [38]. It is increasingly evident that in utero environment can program later susceptibility to breast cancer [39]. The findings of our present study suggest that breast cancer risk can be determined even earlier through diet-induced changes in paternal germ cells before conception. Our study shows that, compared with female offspring of control diet-fed fathers, offspring of lard-fed fathers did not differ in tumor latency, growth, or multiplicity. However, female offspring of lard-fed fathers had increased elongation of the mammary epithelial tree, number of TEBs, and tumor incidence compared with both control diet- and corn oil-fed fathers, showing that paternal exposure to a lard-based high-fat diet containing SFA increased their daughters' mammary cancer risk. TEBs are considered sites of tumor initiation [40], and increased epithelial elongation reflects rapid epithelial growth [41]. Additionally, female offspring of lard-fed fathers showed increased cell proliferation and decreased apoptosis in the mammary gland lobules compared with female offspring of both control diet- and corn oil-fed fathers. Altogether, these findings support the view that altered mammary gland development represents a potential underlying mechanism of increased breast cancer risk [42].

Compared with female offspring of control diet-fed fathers, female offspring of corn oil-fed fathers had decreased tumor growth. There was no difference in tumor incidence, latency, or multiplicity between female offspring of control diet- and corn oil-fed fathers. In addition, female offspring of corn oil-fed fathers had longer tumor latency, decreased tumor growth, and decreased multiplicity compared with female offspring of lard-fed fathers. These data show that paternal exposure to a corn oilbased high-fat diet containing n-6 PUFA had an effect opposite that of a lard-based high-fat diet and reduced their daughters' mammary cancer risk.

Although male rats that were fed the lard-based and corn oil-based high-fat diets consumed the same amount of calories, lard increased the body weight and size of epididymal fat pads more than corn oil did. Thus, different fatty acids can have distinct effects on adipose accumulation, as already shown by others [43]. Our results further show that lard, but not corn oil, elicited detrimental effects on male reproductive parameters (fewer normal sperm cells and lower daily sperm production). 
This is in line with earlier human and animal data showing that SFA disrupt testicular metabolism and sperm quality, while PUFA are essential for sperm cell membrane fluidity and flexibility as well as fertilization [44]. Excessive epididymal fat in lard-fed males may have been detrimental to spermatogenesis, as epididymal tissue is an essential depot for spermatogenesis [45]. The adverse effects of lard may not be mediated through increased insulin resistance. Although a correlation between insulin resistance and impaired sperm production has been reported in rats fed a diet high in SFA [46], as also found in the present study, a corn oil-based high-fat diet also impaired insulin tolerance but did not affect male reproductive parameters. We propose that impaired sperm quality and function in lard-fed fathers could be associated with disruption in metabolic programming and increased breast cancer risk among their daughters.

The impact of obesity in fathers leading to metabolic dysfunction in their female offspring was previously observed in rodent studies [10], and it was also seen in our present study. Female offspring of both lard- and corn oil-fed fathers exhibited increased body weight and adiposity. However, only female offspring of lard-fed fathers displayed an impaired insulin response, indicating that the type of dietary fatty acids consumed represents a key factor in metabolic programming through the male germline.

Epigenetic modifications that are necessary for achieving reproductive capacity of male gametes include DNA methylation, histone retention, and expression of noncoding RNAs such as miRNAs [47]. Because miRNAs can modulate the expression of hundreds of mRNAs that affect embryonic development as well as the establishment of the offspring's epigenome [48], they have been proposed to mediate paternal programming effects on the offspring [49]. The epididymis has been implicated as the site of the alterations of miRNA signatures occurring during the maturation of sperm cells, and therefore an increase in epididymal fat pad size could potentially impact inheritance of miRNA signatures and/ or the developmental trajectory of the offspring [50]. The impact of high-fat-diet-induced male obesity on the miRNA profile in mature spermatozoa has been examined in rodent studies [51]. In a study by Fullston et al. [52], males fed a high-saturated-fat diet exhibited changes in miRNAs in the testes and mature spermatozoa that target mRNA associated with spermatogenesis, embryonic development, and metabolic diseases in the offspring. We provide further evidence that paternal nutrition can impact the sperm miRNA profile and possibly the subsequent mammary gland miRNA profile, which in turn targets genes implicated in breast cancer and other diseases.

Some of the miRNAs that were differentially expressed in the lard- and corn oil-fed fathers' germ cells also were differentially expressed in their daughters' mammary glands, although the daughters were never directly exposed to the high-fat diets. When we compared lard-fed fathers and their daughters, we observed three miRNA that were significantly altered in both the sperm and mammary glands of corn oil-fed fathers and their daughters: miR-1897-5p, miR-219-1-3p, and miR-376a\#. Since miRNAs can modulate gene expression by inhibiting the translation of mRNA or by directing their degradation [53], we focused on determining if the expression of the top potentially targeted proteins (Additional file 1: Table S1) was altered in the daughters of lard- or corn oil-fed fathers. Among them, we highlight Pkd1 and Tgfßr1. PKD1 is a serine/threonine kinase that is expressed in ductal epithelial cells of the mammary gland, maintains the epithelial phenotype, and prevents EMT [54]. Inhibition of PKD1 can lead to pathological conditions such as cancer [55]. Thus, our finding of increased Pkd1 levels in the mammary glands of corn oil-fed fathers' offspring, compared with female offspring of lard-fed fathers, is in line with their lowest susceptibility to breast cancer. In addition, compared with female offspring of control dietand corn oil-fed fathers, another miRNA target, Tgf $\beta r 1$, was increased in the daughters of lard-fed fathers that displayed the highest susceptibility to mammary cancer. $\operatorname{Tgf} \beta \mathrm{r} 1$ expression is related to promotion of breast carcinogenesis through multiple mechanisms, including enhancing EMT [56]. We assessed the protein levels of up- and downstream signaling partners of Tgfßr1. Female offspring of lard-fed fathers showed higher protein levels of Tgf $\beta$ than female offspring of both control diet- and corn oil-fed fathers, as well as higher protein levels of Akt and p-Jnk than control diet-fed fathers. In addition, female offspring of corn oil-fed rats had lower levels of Mtor, Mkk4, and p-Smad3/Smad3 than female offspring of lardfed fathers. These proteins collectively play important roles in cell survival, growth, migration, and invasion $[57,58]$. These findings indicate that mechanisms other than miRNAs contribute to changes in gene expression in the daughters' mammary tissue following paternal exposure to a lard-based high-fat diet.

Because fathers, mothers, and their daughters tend to share the same nutritional habits [59], it is important to further investigate if paternally programmed breast cancer risk is affected by maternal and female offspring's fat intake. Maternal intake of a high corn oil diet during pregnancy increases female offspring's mammary cancer risk [8], while intake of lard has opposite effects [9]. In addition, because obesity-induced altered sperm miRNA expression in the fathers can be normalized through exercise or dietary intervention (consumption of balanced diet), which then improves the metabolic health of female offspring [60], the efficacy of a similar intervention in reducing daughters' breast cancer risk should be investigated. 


\section{Conclusions}

In the present study, we show that paternal intake of a lard-based high-fat diet rich in SFA increases female offspring's mammary cancer risk, as indicated by the increased elongation of the mammary epithelial tree, number of TEBs, and tumor incidence in female offspring of lard-fed fathers compared with female offspring of both control diet- and corn oil-fed rats. However, if the paternal fat source is corn oil that is high in n-6 PUFA, these male rats' offspring's mammary cancer risk is reduced, as indicated by decreased tumor growth in female offspring of corn oil-fed fathers compared with female offspring of both control diet- and lard-fed fathers, as well as by longer tumor latency and decreased tumor multiplicity compared with female offspring of lard-fed fathers. Altered miRNA expression in fathers' sperm and daughters' mammary glands may at least underlie these effects, but other epigenetic changes are likely to be involved. Our findings highlight the importance of paternal nutrition in affecting future generations' risk of developing breast cancer.

\section{Additional file}

Additional file 1: Table S1. Canonical IPA analyses of the target pathways and molecules modulated by altered miRNA from father's sperm and 50-day-old female offspring mammary glands from lard-fed (LB) and corn oil-fed (CB) males. (DOC $31 \mathrm{~kb})$

\begin{abstract}
Abbreviations
Akt, v-akt murine thymoma viral oncogene; ANOVA, analysis of variance; Casp3, caspase 3; CB, rats that were fed a corn oil-based high-fat diet and

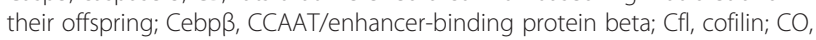
rats that were fed a control diet and their offspring; c-Raf, v-raf leukemia viral oncogene; DMBA, 7,12-dimethylbenz[a]anthracene; EMT, epithelial-tomesenchymal transition; Erk1/2, extracellular signal-regulated kinase 1/2; lgf1r, insulin-like growth factor 1 receptor; ITT, insulin tolerance test; LB, rats that were fed a lard-based high-fat diet and their offspring; LSD, least significant difference; miRNA or miR, microRNA; Mkk4, mitogen-activated protein kinase kinase 4; mRNA, messenger RNA; Mtor, mechanistic target of rapamycin; MUFA, monounsaturated fatty acid; p38, mitogen-activated protein kinase 14; p-Jnk, phosphorylated mitogen-activated protein kinase 8; Pkd1, protein kinase D1; p-Smad3/Smad3, phosphorylated Smad family member 3/Smad family member 3 ratio; PTEN, phosphatase and tensin homolog; PUFA, polyunsaturated fatty acid; Ras, Harvey rat sarcoma virus oncogene; SCLB, somatic cell lysis buffer; SFA, saturated fatty acid; TEB, terminal end bud; Tgf $\beta r 1$, transforming growth factor, beta receptor I
\end{abstract}

\section{Acknowledgements}

We thank the following Georgetown Lombardi Cancer Center Shared Resources (SR) for their assistance: Animal Model SR, Histopathology \& Tissue SR, and Genomics \& Epigenomics SR. We also thank Luciane F. L. Macedo (Faculty of Pharmaceutical Sciences, University of São Paulo) for technical assistance with the dietary fatty acid quantification, Prof. Odair Aguiar Jr. (Federal University of São Paulo) for technical support with the male reproductive parameters analysis, Prof. Luis Fernando Barbisan (Institute of Biosciences, State University of São Paulo) for technical support with cell apoptosis analysis, and Prof. Fernando Salvador Moreno (Faculty of Pharmaceutical Sciences, University of São Paulo) for technical support with the rat experimental protocol.

\section{Funding}

This study was supported by the Brazilian National Council for Scientific and Technological Development (CNPq; process 153478/2012-8), the São Paulo State Research Funding Agency (FAPESP; process 2011/23259-4), the National Cancer Institute (grant R01 CA164384 to LHC), and the Prevent Cancer Foundation (research grant 299045 to SdA).

\section{Authors' contributions}

CCF conceived of the study; supervised animal work, tissue collection, and molecular analysis; and drafted the manuscript. LNG assisted with animal studies, tissue collection, and molecular assays and helped to revise the manuscript. MPR assisted with animal studies, tissue collection, and molecular assays and helped to revise the manuscript. FdOA assisted with animal study design and data analyses and helped to revise the manuscript. $\sqcup$ performed miRNA data analysis and helped to revise the manuscript. Jl assisted with tumor and statistical analyses and helped to revise the manuscript. VCP conducted male reproductive parameter analysis and helped to revise the manuscript. IAdC conducted analysis of the diets' lipid profiles and helped to revise the manuscript. LHC provided intellectual input and helped to draft the manuscript. SdA provided intellectual input and helped to draft the manuscript. TPO conceived of the study, oversaw the research, and drafted the manuscript. All authors read and approved the final manuscript.

\section{Competing interests}

The authors declare that they have no competing financial or non-financial competing interests.

\section{Author details}

${ }^{1}$ Department of Food and Experimental Nutrition, Faculty of Pharmaceutical Sciences, University of São Paulo, Avenida Professor Lineu Prestes 580, Bloco 14, São Paulo, SP 05508-000, Brazil. ' Georgetown Lombardi Comprehensive Cancer Center, Washington, DC 20007, USA. ${ }^{3}$ Food Research Center (FoRC), São Paulo 05508-000, Brazil.

Received: 20 January 2016 Accepted: 17 June 2016

Published online: 26 July 2016

\section{References}

1. Ferlay J, Soerjomataram I, Ervik M, Dikshit R, Eser S, Mathers C, Rebelo M, Parkin DM, Forman D, Bray F. GLOBOCAN 2012 v1.0: estimated cancer incidence, mortality and prevalence worldwide in 2012. Lyon, France: International Agency for Research on Cancer; 2013. http://globocan.iarc.fr. Accessed 17 Nov 2015.

2. Rahib L, Smith BD, Aizenberg R, Rosenzweig AB, Fleshman JM, Matrisian LM. Projecting cancer incidence and deaths to 2030: the unexpected burden of thyroid, liver, and pancreas cancers in the United States. Cancer Res. 2014;74:2913-21.

3. Howell A, Anderson AS, Clarke RB, Duffy SW, Evans DG, Garcia-Closas M, Gescher AJ, Key TJ, Saxton JM, Harvie MN. Risk determination and prevention of breast cancer. Breast Cancer Res. 2014;16:446.

4. Albuquerque RC, Baltar VT, Marchioni DM. Breast cancer and dietary patterns: a systematic review. Nutr Rev. 2014;72:1-17.

5. Cordain L, Eaton SB, Sebastian A, Mann N, Lindeberg S, Watkins BA, O'Keefe $\mathrm{JH}$, Brand-Miller J. Origins and evolution of the Western diet: health implications for the 21st century. Am J Clin Nutr. 2005;81:341-54.

6. Lawrence GD. Dietary fats and health: dietary recommendations in the context of scientific evidence. Adv Nutr. 2013;4:294-302.

7. Colditz GA, Bohlke K, Berkey CS. Breast cancer risk accumulation starts early: prevention must also. Breast Cancer Res Treat. 2014;145:567-79.

8. Hilakivi-Clarke L, Clarke R, Onojafe I, Raygada M, Cho E, Lippman M. A maternal diet high in $\mathrm{n}-6$ polyunsaturated fats alters mammary gland development, puberty onset, and breast cancer risk among female rat offspring. Proc Natl Acad Sci U S A. 1997;94:9372-7.

9. De Oliveira AF, Fontelles CC, Rosim MP, de Oliveira TF, de Melo Loureiro AP, Mancini-Filho J, Rogero MM, Moreno FS, de Assis S, Barbisan LF, HilakiviClarke L, Ong TP. Exposure to lard-based high-fat diet during fetal and lactation periods modify breast cancer susceptibility in adulthood in rats. $J$ Nutr Biochem. 2014;25:613-22.

10. Ng SF, Lin RC, Laybutt DR, Barres R, Owens JA, Morris MJ. Chronic high-fat diet in fathers programs $\beta$-cell dysfunction in female rat offspring. Nature. 2010;467:963-6. 
11. Watkins AJ, Sinclair KD. Paternal low protein diet affects adult offspring cardiovascular and metabolic function in mice. Am J Physiol Heart Circ Physiol. 2014;306:H1444-52.

12. Hughes V. Epigenetics: the sins of the father. Nature. 2014;507:22-4

13. Titus-Ernstoff L, Egan KM, Newcomb PA, Ding J, Trentham-Dietz A, Greenberg ER, Baron JA, Trichopoulos D, Willett WC. Early life factors in relation to breast cancer risk in postmenopausal women. Cancer Epidemiol Biomarkers Prev. 2002;11:207-10.

14. de Kok IM, van Lenthe FJ, Avendano M, Louwman M, Coebergh JW, Mackenbach JP. Childhood social class and cancer incidence: results of the GLOBE study. Soc Sci Med. 2008;66:1131-9.

15. Hanna CB, Hennebold JD. Ovarian germline stem cells: an unlimited source of oocytes? Fertil Steril. 2014;101:20-30.

16. Romero $Y$, Calvel P, Nef S. Non-coding small RNAs and spermatogenesis. Med Sci. 2012;28:490-6.

17. Godmann M, Lambrot R, Kimmins S. The dynamic epigenetic program in male germ cells: its role in spermatogenesis, testis cancer, and its response to the environment. Microsc Res Tech. 2009;72:603-19.

18. Gill ME, Erkek S, Peters AH. Parental epigenetic control of embryogenesis: a balance between inheritance and reprogramming? Curr Opin Cell Biol. 2012;24:387-96.

19. Dean W. DNA methylation and demethylation: a pathway to gametogenesis and development. Mol Reprod Dev. 2014;81:113-25.

20. Aiken CE, Ozanne SE. Transgenerational developmental programming. Hum Reprod Update. 2014;20:63-75.

21. Soubry A, Hoyo C, Jirtle RL, Murphy SK. A paternal environmental legacy: evidence for epigenetic inheritance through the male germ line. Bioessays. 2014;36:359-71.

22. Varela-Moreiras G. Controlling obesity: what should be changed? Int J Vitam Nutr Res. 2006;76:262-8.

23. Nettleton JA, Jebb S, Risérus U, Koletzko B, Fleming J. Role of dietary fats in the prevention and treatment of the metabolic syndrome. Ann Nutr Metab. 2014:64:167-78.

24. Association of Official Analytical Chemists (AOAC). Fat (Total, Saturated and Unsaturated) in Foods. In: Horwitz W, editor. Official methods of analysis of AOAC International. Vol 2 Food composition; Additives; Natural contaminants. 17th edition. Rockville, MD, USA. Gaithersburg, Md: AOAC International; 2002. p. 20-4.

25. Hartman L, Lago RC. Rapid preparation of fatty acid methyl esters from lipids. Lab Pract. 1973;22:45-6.

26. Takada J, Fonseca-Alaniz MH, de Campos TB, Andreotti S, Campana AB, Okamoto M, Borges-Silva Cd, Machado UF, Lima FB. Metabolic recovery of adipose tissue is associated with improvement in insulin resistance in a model of experimental diabetes. J Endocrinol. 2008;198:51-60.

27. Le Floch JP, Escuyer P, Baudin E, Baudon D, Perlemuter L. Blood glucose area under the curve: methodological aspects. Diabetes Care. 1990;13:172-5.

28. Goodrich R, Johnson G, Krawetz SA. The preparation of human spermatozoal RNA for clinical analysis. Arch Androl. 2007;53:161-7.

29. Robb GW, Amann RP, Killian GJ. Daily sperm production and epididymal sperm reserves of pubertal and adult rats. J Reprod Fertil. 1978;54:103-7.

30. Seed J, Chapin RE, Clegg ED, Dostal LA, Foote RH, Hurtt ME, et al. Methods for assessing sperm motility, morphology, and counts in the rat, rabbit, and dog: a consensus report. ILSI Risk Science Institute Expert Working Group on Sperm Evaluation. Reprod Toxicol. 1996:10:237-44.

31. de Assis S, Warri A, Cruz MI, Hilakivi-Clarke L. Changes in mammary gland morphology and breast cancer risk in rats. J Vis Exp. 2010;44:2260.

32. Spang-Thomsen M, Rygaard K, Hansen L, Halvorsen AC, Vindeløv LL, Brünner N. Growth kinetics of four human breast carcinomas grown in nude mice. Breast Cancer Res Treat. 1989;14:235-43.

33. Elmore SA, Dixon D, Hailey JR, Harada T, Herbert RA, Maronpot RR, Nolte T, Rehg JE, Rittinghausen S, Rosol TJ, Satoh H, Vidal JD, Willard-Mack CL, Creasy DM. Recommendations from the INHAND Apoptosis/Necrosis Working Group. Toxicol Pathol. 2016;44:173-88.

34. Brattelid T, Aarnes EK, Helgeland E, Guvaåg S, Eichele H, Jonassen AK. Normalization strategy is critical for the outcome of miRNA expression analyses in the rat heart. Physiol Genomics. 2011;43:604-10

35. Shen B, Zhou S, He Y, Zhao H, Mei M, Wu X. Revealing the underlying mechanism of ischemia reperfusion injury using bioinformatics approach. Kidney Blood Press Res. 2013;38:99-108.

36. Du C, Zhang C, Hassan S, Biswas MH, Balaji KC. Protein kinase D1 suppresses epithelial-to-mesenchymal transition through phosphorylation of Snail. Cancer Res. 2010;70:7810-9.
37. Wendt MK, Tian M, Schiemann WP. Deconstructing the mechanisms and consequences of TGF- $\beta$-induced EMT during cancer progression. Cell Tissue Res. 2012;347:85-101.

38. Molina-Montes E, Pérez-Nevot B, Pollán M, Sánchez-Cantalejo E, Espín J, Sánchez MJ. Cumulative risk of second primary contralateral breast cancer in BRCA1/BRCA2 mutation carriers with a first breast cancer: a systematic review and meta-analysis. Breast. 2014;23:721-42.

39. De Assis S, Hilakivi-Clarke L. Timing of dietary estrogenic exposures and breast cancer risk. Ann N Y Acad Sci. 2006;1089:14-35.

40. Snyderwine EG. Mammary gland carcinogenesis by 2-amino-1-methyl-6 phenylimidazo[4,5-b]pyridine in rats: possible mechanisms. Cancer Lett. 1999;143:211-5.

41. Hovey RC, McFadden TB, Akers RM. Regulation of mammary gland growth and morphogenesis by the mammary fat pad: a species comparison. J Mammary Gland Biol Neoplasia. 1999;4:53-68.

42. de Assis S, Khan G, Hilakivi-Clarke L. High birth weight increases mammary tumorigenesis in rats. Int J Cancer. 2006;119:1537-46.

43. Gouk SW, Cheng SF, Ong AS, Chuah CH. Stearic acids at sn-1, 3 positions of TAG are more efficient at limiting fat deposition than palmitic and oleic acids in C57BL/6 mice. Br J Nutr. 2014;111:1174-80.

44. Rato L, Alves MG, Cavaco JE, Oliveira PF. High-energy diets: a threat for male fertility? Obes Rev. 2014;15:996-1007.

45. Chu Y, Huddleston GG, Clancy AN, Harris RB, Bartness TJ. Epididymal fat is necessary for spermatogenesis, but not testosterone production or copulatory behavior. Endocrinology. 2010;151:5669-79.

46. Reame V, Pytlowanciv EZ, Ribeiro DL, Pissolato TF, Taboga SR, Góes RM, Pinto-Fochi ME. Obesogenic environment by excess of dietary fats in different phases of development reduces spermatic efficiency of Wistar rats at adulthood: correlations with metabolic status. Biol Reprod. 2014;91:151.

47. Wu H, Hauser R, Krawetz SA, Pilsner JR. Environmental susceptibility of the sperm epigenome during windows of male germ cell development. Curr Environ Health Rep. 2015;2:356-66.

48. Gaskins AJ, Colaci DS, Mendiola J, Swan SH, Chavarro JE. Dietary patterns and semen quality in young men. Hum Reprod. 2012;27:2899-907.

49. McPherson NO, Fullston T, Aitken RJ, Lane M. Paternal obesity, interventions, and mechanistic pathways to impaired health in offspring. Ann Nutr Metab. 2014:64:231-8.

50. Nixon B, Stanger SJ, Mihalas BP, Reilly JN, Anderson AL, Tyagi S, Holt JE, McLaughlin EA. The microRNA signature of mouse spermatozoa is substantially modified during epididymal maturation. Biol Reprod. 2015;93:91.

51. McPherson NP, Fullston T, Bakos HW, Setchell BP, Lane M. Obese father's metabolic state, adiposity, and reproductive capacity indicate son's reproductive health. Fertil Steril. 2014;101:865-73.

52. Fullston T, Ohlsson Teague EM, Palmer NO, DeBlasio MJ, Mitchell M, Corbett M, Print CG, Owens JA, Lane M. Paternal obesity initiates metabolic disturbances in two generations of mice with incomplete penetrance to the F2 generation and alters the transcriptional profile of testis and sperm microRNA content. FASEB J. 2013:27:4226-43.

53. Duk MA, Samsonova MG, Samsonov AM. Dynamics of miRNA driven feedforward loop depends upon miRNA action mechanisms. BMC Genomics. 2014;15 Suppl 12:S9.

54. Bastea LI, Döppler H, Balogun B, Storz P. Protein kinase D1 maintains the epithelial phenotype by inducing a DNA-bound, inactive SNAI1 transcriptional repressor complex. PLoS One. 2012;7:e30459.

55. Ni Y, Wang L, Zhang J, Pang Z, Liu Q, Du J. PKD1 is downregulated in nonsmall cell lung cancer and mediates the feedback inhibition of mTORC1-S6K1 axis in response to phorbol ester. Int J Biochem Cell Biol. 2015;60:34-42.

56. Piek E, Moustakas A, Kurisaki A, Heldin CH, ten Dijke P. TGF- $\beta$ type I receptor/ALK5 and Smad proteins mediate epithelial to mesenchymal transdifferentiation in NMuMG breast epithelial cells. J Cell Sci. 1999;112:4557-68.

57. Guo X, Wang XF. Signaling cross-talk between TGF- $\beta /$ BMP and other pathways. Cell Res. 2009;19:71-88.

58. Zhang YE. Non-Smad pathways in TGF- $\beta$ signaling. Cell Res. 2009;19:128-39.

59. Gruber KJ, Haldeman LA. Using the family to combat childhood and adult obesity. Prev Chronic Dis. 2009;6:A106.

60. McPherson NO, Owens JA, Fullston T, Lane M. Preconception diet or exercise intervention in obese fathers normalizes sperm microRNA profile and metabolic syndrome in female offspring. Am J Physiol Endocrinol Metab. 2015;308:E805-21. 